NBER WORKING PAPER SERIES

CORRECTIVE TAXATION VERSUS LIABILITY

\author{
Steven Shavell \\ Working Paper 16234 \\ http://www.nber.org/papers/w16234 \\ NATIONAL BUREAU OF ECONOMIC RESEARCH \\ 1050 Massachusetts Avenue \\ Cambridge, MA 02138 \\ July 2010
}

I thank Louis Kaplow for helpful discussions and the John M. Olin Center for Law, Economics, and Business at Harvard Law School for research support. The views expressed herein are those of the author and do not necessarily reflect the views of the National Bureau of Economic Research.

NBER working papers are circulated for discussion and comment purposes. They have not been peerreviewed or been subject to the review by the NBER Board of Directors that accompanies official NBER publications.

(C) 2010 by Steven Shavell. All rights reserved. Short sections of text, not to exceed two paragraphs, may be quoted without explicit permission provided that full credit, including $\odot$ notice, is given to the source. 
Corrective Taxation versus Liability

Steven Shavell

NBER Working Paper No. 16234

July 2010

JEL No. H2,K13,K32,Q5

\begin{abstract}
$\underline{\text { ABSTRACT }}$
Taxation and liability are compared here as means of controlling harmful externalities. It is emphasized that liability has an advantage over taxation: inefficiency of incentives arises under taxation when, as would be typical, it would be impractical for a tax to reflect all variables that significantly affect expected harm, whereas efficiency of incentives under liability does not require the state to determine expected harm - it requires only that injurers pay for harm that occurs. However, taxation enjoys an advantage over liability: incentives under liability are diluted to the degree that injurers might escape suit. The optimal joint use of taxation and liability is also examined, and it is shown in the model that is analyzed that liability should be employed fully because liability creates more efficient incentives than taxation; a tax should be used only to take up the slack due to the possibility that suit for harm would not be brought.
\end{abstract}

Steven Shavell

Harvard Law School

1575 Massachusetts Avenue

Hauser Hall 508

Cambridge, MA 02138

and NBER

shavell@law.harvard.edu 


\section{Corrective Taxation versus Liability}

Since the writing of A. C. Pigou (1932), taxes have been emphasized as a means of control of activities that generate harm, especially in the domain of pollution, yet their use is in fact limited (Robert N. Stavins 2003). In contrast, liability has great importance in reducing harm. Much of the vast terrain of accidents - from oil spills, to crane mishaps, to car collisions - is subject to liability but not to taxation. I here compare corrective taxation to liability in two versions of a model, with a view toward shedding light on the difference in their application. ${ }^{1}$

In the first version, the danger from an injurer's activity depends on factors that vary among injurers. For example, the probability and seriousness of an oil spill due to an oil tanker accident will depend on the the strength of the tanker's hull and the vulnerability of fishing activity and tourism to a spill; and the expected harm from a crane accident will depend on characteristics of the crane and the exposure to risk of nearby buildings and passersby. I assume that it is impractical for the tax to be based on many such variables and for simplicity that the tax is a function only of an injurer's level of activity (amount of oil transported, number of uses of a crane). Hence, the tax will not induce injurers to choose their levels of activity optimally.

Under liability, an injurer who is sued is presumed to pay for the harm that occurs. ${ }^{2}$ Thus, if suit for harm were always brought, an injurer's expected liability would

\footnotetext{
${ }^{1}$ Almost no attention has been paid to liability as an alternative to corrective taxation; however, Shavell (2011) compares taxation to liability in a broad, though informal manner. In contrast, many articles consider regulation as an alternative to taxation; see for example, the survey in Bovenberg and Goulder (2002).

${ }^{2}$ This is known as strict liability. I do not examine the other major form of liability based on negligence but it is considered in Shavell (2011).
} 
equal expected harm, so injurers would choose optimal levels of activity. Further, this would occur without the state needing information about the danger of activities; to impose liability requires only that the state determine the harm that eventuates (the state need not gauge the risk of an oil spill; it need only measure the harm from a spill that occurs). However, it is assumed that suit is not always brought, for harm may be hard to trace to its author and it may be too low to make suit worthwhile. Consequently, expected liability will be less than expected harm ${ }^{3}$ and levels of activity will be excessive.

It follows that the comparison of the tax with liability depends on a comparison of the inefficiency of the tax caused by variation in the danger of activities with the inefficiency of liability caused by escape from suit.

Joint use of taxation and liability is also considered. It is shown that liability should be imposed to the complete extent - injurers who are sued should pay for the entire harm - but, under a general condition, the tax should be less than expected harm. In essence, liability should be employed fully because it creates a more efficient incentive than taxation; the tax should be used only to take up the slack due to the possibility that suit for harm would not be brought.

In the second version of the model, injurers are assumed to be identical in order to focus on another issue: injurers may choose not only a level of activity but also riskreducing actions, such as safety training of the crew of an oil tanker, the hiring of a pilot boat to accompany the tanker when entering or leaving port, or installation of a sonar

\footnotetext{
${ }^{3}$ Expected liability will also be less than expected harm if injurers do not have assets sufficient to pay for the full harm. This problem of asset insufficiency is less serious for taxation than for liability because the tax, being based on expected harm rather than actual harm, can often be paid in full even though the actual harm cannot. For simplicity, the problem of asset insufficiency (the judgment proof problem) is not studied in the model here but it is discussed in Shavell (2011).
} 
system. The tax is presumed not to incorporate such precautions, for they may be costly to verify or be chosen after the tax is imposed. Thus, under the tax, no precautions will be taken in the model, making the risk per unit of activity inefficiently high. However, the level of activity will be correct given the excessive risk (the level of use of oil tankers will be appropriate given that they create excessive danger of spills).

Under liability, in contrast, having to pay for harm creates incentives to choose positive precautions. But the possibility that suit would not be brought means that the level of precautions will be too low and the level of activity too high.

Hence, the comparison between taxes and liability depends on the tax-related problem of the absence of incentives to exercise precautions versus the problem of diluted incentives to exercise precautions and to moderate levels of activity due to escape from suit. Under optimal joint use of taxes and liability, liability is again employed to the full extent, and the tax equals only the fraction of expected harm that is unaccounted for by liability.

The conclusions from the model lead to two broad conjectures: First, in the general context of pollution of the atmosphere or large bodies of water, the tax may be superior to liability, for there may be relatively little variability among parties in expected harm per unit of pollutant discharged, whereas suit might not be likely, especially because of difficulty in proving the source of harm. But second, in most of the domain of externalities (exemplified by oil spills and crane accidents), liability may be superior to the tax, due to the significance of variability among parties in expected harm and of opportunities to take precautions. 


\section{Model with Expected Harm Varying Across Injurers}

Let $x$ be an injurer's level of harmful activity (amount of oil transported by tanker, quantity of pollutant discharged) and $b(x)$ be the benefit of an injurer, where $b(0)=0$, $b^{\prime}(0)>0$, and $b$ is concave in $x$. Let $y$ be the expected harm per unit of $x$, so that the total expected harm caused by an injurer is $x y$, and let $f(y)$ be the density of $y$ across injurers. Assume that social welfare is $\int_{0}^{\infty}[b(x)-x y] f(y) d y$, where $x$ may depend on $y$. The firstbest $x$ of an injurer of type $y$ is determined by $b^{\prime}(x)=y$ and is denoted $x^{*}(y) ; x^{*}(y)$ is decreasing in $y$ (from implicit differentiation of $b^{\prime}(x)=y$ ) - the more dangerous the activity, the lower its optimal level. Hence, first-best social welfare is $\int_{0}^{\infty}\left[b\left(x^{*}(y)\right)-\right.$ $x *(y)) y] f(y) d y$.

Under a tax regime, an injurer who chooses activity level $x$ pays $t x$ in taxes, where $t$ cannot depend on $y$, since as explained in the introduction the state is assumed to be unable to observe $y$. An injurer therefore selects $x$ to maximize $b(x)-t x$ regardless of his

$y$. Thus all injurers choose $x^{*}(t)$ and social welfare is $\int_{0}^{\infty}\left[b\left(x^{*}(t)\right)-x^{*}(t) y\right] f(y) d y=b\left(x^{*}(t)\right)$ $-x^{*}(t) \mathrm{E}(y)$, where $\mathrm{E}(y)$ is the mean of $y$. Since $b(x)-x \mathrm{E}(y)$ is maximized at $x^{*}(\mathrm{E}(y))$, the optimal tax $t^{*}$ must be $\mathrm{E}(y)$ and social welfare is $W_{T}=b(x *(\mathrm{E}(y)))-x *(\mathrm{E}(y)) \mathrm{E}(y)$. In summary, we have

PROPOSITION 1: The optimal tax $t^{*}=\mathrm{E}(y)$, the mean expected harm per unit of activity over the population of injurers. Under $t^{*}$, all injurers choose the same level of activity, $x *(\mathrm{E}(y))$, which is not ideal; $x *(\mathrm{E}(y))$ is too low for injurers with $y<\mathrm{E}(y)$ and excessive for injurers with $y>\mathrm{E}(y)$. Social welfare is $W_{T}$. 
Under a liability regime, an injurer who is sued pays for the harm caused. Hence, the state must be assumed to be able to verify the harm when accidents occur (which is not inconsistent with the assumption that the expected harm $y$ is unobservable). Let $p$ be the probability that suit for harm would be brought, where $0<p<1$. Accordingly, an injurer chooses $x$ to maximize $b(x)-p x y$, so that $x^{*}(p y)$ is selected. ${ }^{4}$ Note that although $x^{*}(p y)$ reflects $y$, it is excessive, $x^{*}(p y)>x^{*}(y)$ because $p<1$. Social welfare is given by $\left.W_{L}=\int_{0}^{\infty}\left[b\left(x^{*}(p y)\right)-x^{*}(p y)\right) y\right] f(y) d y$. We therefore have

PROPOSITION 2: Under liability, where $0<p<1$ is the probability of suit, injurers choose activity levels $x *(p y)$. Although the activity level declines with the expected harm $y$, it is excessive. Social welfare is $W_{L}$.

From what has been said, it is apparent how the tax and liability compare. PROPOSITION 3: Liability is superior to the tax if and only if the probability of suit $p$ is above a positive threshold $p^{*}<1$. The tax is superior to liability if the variability in expected harm $y$ is sufficiently small ( $y$ is sufficiently concentrated about $\mathrm{E}(y)$ ).

With respect to the first claim, note that $W_{L}<W_{T}$ at $p=0, W_{L}$ is increasing in $p$, and $W_{L}$ is first-best at $p=1$. Hence, the asserted threshold $p^{*}$ must exist. Regarding the second claim, note that $b\left(x^{*}(\mathrm{E}(y))-x^{*}(\mathrm{E}(y)) \mathrm{E}(y)>b\left(x^{*}(p \mathrm{E}(y))\right)-x^{*}\left(p \mathrm{E}^{*}(y)\right) \mathrm{E}(y)\right.$. Hence $b\left(x^{*}(\mathrm{E}(y))-x^{*}(\mathrm{E}(y)) y>b\left(x^{*}(p y)\right)-x^{*}(p y) y\right.$ for $y$ in a neighborhood of $\mathrm{E}(y)$.

Accordingly, if enough probability mass is contained in this neighborhood, the tax will be superior to liability.

\footnotetext{
${ }^{4}$ In supposing that expected liability is $p x y$, I implicitly assume that if harm $h$ occurs and the injurer is sued, the injurer's liability payment cannot exceed $h$ - I ignore the possibility of increasing liability to $h / p$. Were this done, expected liability would apparently be $x y$. However, if the finiteness of assets were recognized, then $h / p$ might exceed assets. Hence, expected liability would be less than expected harm, and the qualitative nature of the analysis of taxation and liability would be essentially the same as here.
} 
Assume now that both a tax $t$ and liability are employed. To allow for the possibility of partial liability, let $\lambda \leq 1$ be the fraction of harm that an injurer pays if found liable. Hence, an injurer chooses $x$ to maximize $b(x)-t x-\lambda p x y$, so that $x$ is $x^{*}(t+\lambda p y)$. Social welfare is therefore $W_{T L}=\int_{0}^{\infty}\left[b\left(x^{*}(t+\lambda p y)\right)-x^{*}(t+\lambda p y) y\right] f(y) d y$, and we can demonstrate the following.

PROPOSITION 4: Under the optimal joint tax and liability regime, liability is employed to the full extent - the fraction $\lambda$ of harm paid by an injurer is 1 . Also, the optimal tax $t^{* *}$ is positive; and $t^{* *}<t^{*}=\mathrm{E}(y)$ provided that injurer benefits $b$ display decreasing absolute risk aversion.

The intuition supporting the first claim is that liability is a superior incentive to the tax because only under liability do expected payments reflect an individual injurer's expected harm $y$. To demonstrate the claim, assume first that $t=0$. Then if $\lambda<1, x$ is $x^{*}(\lambda p y)>$ $x^{*}(p y)>x^{*}(y)$. From this and the concavity of $b(x)-x y$ in $x$, we have $b\left(x^{*}(p y)\right)-x^{*}(p y) y$ $>b\left(x^{*}(\lambda p y)\right)-x^{*}(\lambda p y) y$. Hence, $W_{T L}$ is higher at $\lambda=1$ than at $\lambda<1$, showing the claim.

Next assume that $t>0$ and let $x(y)=x^{*}(t+\lambda p y)$. Note first that $x(y) \operatorname{crosses} x^{*}(y)$ once at $y_{c}=t /(1-\lambda p)$. In particular, at a crossing point, $b^{\prime}(x)=y=t+\lambda p y$, implying that $y_{c}$ is as stated. Now to show that $\lambda=1$ is optimal, I demonstrate that if $\lambda<1$, we can increase $W_{T L}$ by raising $\lambda$ and lowering $t$. Specifically, raise $\lambda$ by $\delta$ such that $\lambda+\delta<1$, and lower $t$ by $\tau$ such that $\hat{x}(y)$ also crosses $x^{*}(y)$ at $y_{c}=t /(1-\lambda p)$, where $\hat{x}(y)=x^{*}(t-\tau+$ $(\lambda+\delta) p y)$. This will be so if $(t-\tau)+(\lambda+\delta) p y_{c}=y_{c}$, implying that $\tau=\delta p y_{c}$. By picking $\delta$ sufficiently small, we can guarantee that $t-\tau>0$. To prove that $W_{T L}$ will be higher, consider $y<y_{c}$ (an analogous argument applies for $\left.y>y_{c}\right)$. I claim that $y<(t-\tau)+(\lambda+$ $\delta) p y<t+\lambda p y$. This inequality will establish that the integrand of $W_{T L}$ is higher for $y<$ 
$y_{c}$, since $b(x)-x y$ is concave in $x$ and it implies that $x^{*}(y)>\hat{x}(y)>x(y)$. Now the right side of the inequality is equivalent to $\delta p y<\tau$, which follows from $\tau=\delta p y_{c}$. Also, as $(t-$ $\tau)+(\lambda+\delta) p y_{c}=y_{c}$, the middle term of the inequality equals $y_{c}-(\lambda+\delta) p\left(y_{c}-y\right)$. But the latter exceeds $y_{c}-\left(y_{c}-y\right)=y$.

With regard to $t^{* *}$, note that $\left.d W_{T L} / d t=\int_{0}^{\infty} x^{*^{\prime}}(t+\lambda p y)\left[b^{\prime}\left(x^{*}(t+\lambda p y)\right)-y\right)\right] f(y) d y$.

This is positive at $t=0$ since $x^{* \prime}(\lambda p y)<0$ and since $b^{\prime}\left(x^{*}(\lambda p y)\right)=\lambda p y<y$. Hence $t^{* *}>0$. The claim that $t^{* *}<\mathrm{E}(y)$ given decreasing absolute risk aversion of $b$ is proved in the Appendix.

\section{Model with Expected Harm a Function of Precautions}

Now consider a modification of the foregoing model in which injurers are identical and the expected harm per unit of activity is $y=y(e)$, where $e$ is precautions to reduce the probability or magnitude of harm when engaging in an activity, and $y$ is positive and decreasing and convex in $e$. Assume that social welfare is $b(x)-(y(e)+e) x$, benefits less the total expected harm and costs of precautions. It is clear that first-best precautions $e^{*}$ minimize $y(e)+e$, so $e^{*}$ is determined by $y^{\prime}(e)=-1$. Hence, the ideal activity level $x^{*}$ maximizes $b(x)-\left(y\left(e^{*}\right)+e^{*}\right) x$, so $x^{*}$ is determined by $b^{\prime}(x)=y\left(e^{*}\right)+e^{*}$. More generally, for any positive $z$, let $x^{*}(z)$ be determined by $b^{\prime}(x)=z$, so that $x *(z)$ is the optimal level of activity if the social cost per unit of activity is $z$.

Under the tax regime, an injurer pays $t x$ in taxes, where $t$ cannot depend on $y$ or $e$ because, as noted in the introduction, the state is assumed not to be able to observe them. Hence, injurers choose $e$ and $x$ to maximize $b(x)-(t+e) x$. Thus, they choose $e=0$ and $x$ to maximize $b(x)-t x$. Since social welfare is $b(x)-y(0) x$, it is clear that the optimal tax 
$t^{*}$ given $y(0)$ is $y(0)$. Hence, social welfare $W_{T}$ will be $b\left(x^{*}(y(0))\right)-y(0) x^{*}(y(0))$ under $t^{*}$. That is, we have

PROPOSITION 5: Under the tax regime, injurers exercise no precautions, so that expected harm per unit of activity $y(0)$ is excessive. The optimal tax $t^{*}=y(0)$ and the level of activity is $x^{*}(y(0))$, which is optimal given $y(0)$. Social welfare is $W_{T}$.

Under liability, injurers choose $e$ and $x$ to maximize $b(x)-(p y(e)+e) x$. Therefore, they choose $e$ to minimize $p y(e)+e$ and their choice $e_{L}$ is determined by $p y^{\prime}(e)=-1$; hence $e^{*}>e_{L}>0$. Accordingly, injurers choose $x^{*}\left(p y\left(e_{L}\right)+e_{L}\right)$, which exceeds the optimal $x$ given $e_{L}$ because $p<1$. Social welfare $W_{L}$ is $b\left(x *\left(p y\left(e_{L}\right)+e_{L}\right)\right)-\left(y\left(e_{L}\right)+\right.$ $\left.e_{L}\right) x *\left(p y\left(e_{L}\right)+e_{L}\right)$. To summarize, we have

PROPOSITION 6: Under liability, injurers exercise positive but less than optimal precautions, $0<e_{L}<e^{*}$. Their level of activity $x *\left(p y\left(e_{L}\right)+e_{L}\right)$ is excessive given $e_{L}$. Social welfare is $W_{L}$.

Regarding the comparison of the tax and liability, we have PROPOSITION 7: Liability is superior to the tax if and only if the probability of suit $p$ is above a positive threshold $p^{*}<1$.

Let $e(p)$ denote an injurer's choice of $e$ given $p$, and note from implicit differentiation of $p y^{\prime}(e)=-1$ that $e^{\prime}(p)>0$. Let $x(p)$ be the injurer's choice of $x$ given $p$ and similarly note that $x^{\prime}(p)<0$. Observe that $W_{L}$ is increasing in $p: d W_{L} / d p=\left(b^{\prime}(x)-y(e)-e\right) x^{\prime}(p)(y(e)+$ $\left.p y^{\prime}(e) e^{\prime}(p)+e^{\prime}(p)\right]-x\left(y^{\prime}(e) e^{\prime}(p)+e^{\prime}(p)\right)$, which, using $b^{\prime}(x)=p y(e)+e$ and $p y^{\prime}(e)=-1$, can be seen to equal $-(1-p) x^{\prime}(p) y^{2}-x e^{\prime}(p)\left(y^{\prime}(e)+1\right)$, which is positive since $x^{\prime}(p)<0$, $e^{\prime}(p)>0$, and $y^{\prime}(e)+1<0$. The proposition now follows since $W_{L}<W_{T}$ at $p=0$ and $W_{L}$ is first-best at $p=1$. 
We next have

PROPOSITION 8: Under the optimal joint tax and liability regime, liability is employed to the full extent - the fraction $\lambda$ of harm paid by an injurer is 1 . Also, the tax $t^{* *}$ equals the expected harm that is uncorrected by liability, namely, $(1-p) y\left(e_{J}\right)$.

Under the joint regime, an injurer's problem is to maximize $b(x)-(t+p \lambda y(e)+e) x$. Hence, $e$ minimizes $p \lambda y(e)+e$, so the choice of $e$, denoted $e_{J}$, is determined by $p \lambda y^{\prime}(e)=-$ 1. Observe that $e^{*}>e_{J}>0$ since $y$ is convex in $e$. Further, $x$ is $x *\left(t+p \lambda y\left(e_{J}\right)+e_{J}\right)$. It is clear that, for any $\lambda$, the optimal $t$ is $(1-p \lambda) y\left(e_{J}\right)$, for then $x$ will be $x *\left(y\left(e_{J}\right)+e_{J}\right)$, that is, optimal given $e_{J}$. Now we can also see that $\lambda$ should be 1 , since if $\lambda<1$ and $\lambda$ is increased, $e_{J}$ will rise closer to $e^{*}$, meaning that $y(e)+e$ will fall (because this term is convex in $e$ ), implying that welfare $b(x)-(y(e)+e) x$ will rise since $x$ will be optimal given $y(e)+e$.

\section{References}

Bovenberg, A. Lans, and Lawrence H. Goulder. 2002. "Environmental Taxation and Regulation." In Vol. 3, Handbook of Public Economics, ed. Alan J. Auerbach and Martin Feldstein, 1471-1545. Amsterdam: Elsevier.

Pigou, A. C. 1932. The Economics of Welfare, fourth ed. London: Macmillan.

Shavell, Steven. Forthcoming. "The Corrective Tax versus Liability As Solutions to the Problem of Harmful Externalities." Journal of Law and Economics.

Stavins, Robert N. 2003. "Experience with Market-Based Environmental Policy Instruments." In Vol. 1, Handbook of Environmental Economics, ed. Karl-Göran Mäler and Jeffrey R. Vincent, 355-435. Amsterdam: Elsevier. 


\section{Appendix}

This appendix contains the proof of the part of Proposition 4 that is not shown in the text, namely, under the optimal joint tax and liability regime, the optimal tax $t^{* *}<$ $\mathrm{E}(y)$ provided that injurer benefits $b(x)$ display decreasing absolute risk aversion.

To establish this claim, observe that under the joint tax and liability regime, social welfare as a function of the tax $t$ is

$$
W_{T L}(t)=\int_{0}^{\infty}\left[b\left(x^{*}(t+p y)\right)-x^{*}(t+p y) y\right] f(y) d y
$$

since it was shown already that $\lambda=1$. Hence

$$
W_{T L}(t)=\int_{0}^{\infty} x^{* \prime}(t+p y)\left[b^{\prime}\left(x^{*}(t+p y)\right)-y\right] f(y) d y,
$$

where $x^{* \prime}(t+p y)$ is the derivative of $x^{*}(t+p y)$ with respect to $t$. It will be shown that

$$
W_{T L}(\mathrm{E}(y))=\int_{0}^{\infty} x^{* \prime}(\mathrm{E}(y)+p y)\left[b^{\prime}\left(x^{*}(\mathrm{E}(y)+p y)\right)-y\right] f(y) d y<0 .
$$

As I will note below, an essentially identical argument to what I am about to give will prove also that $W_{T L}{ }^{\prime}(t)<0$ for any $t>\mathrm{E}(y)$. Hence, it will follow that the optimal tax $t^{* *}$ must be less than $\mathrm{E}(y)$.

Observe first that since the optimal tax under a tax only regime is $\mathrm{E}(y)$ (from Proposition 1), $b\left(x^{*}(t)\right)-x^{*}(t) \mathrm{E}(y)$ is maximized at $t=\mathrm{E}(y)$. Therefore, $b^{\prime}\left(x^{*}(\mathrm{E}(y))\right) x^{* \prime}(\mathrm{E}(y))-x^{* \prime}(\mathrm{E}(y)) \mathrm{E}(y)=0$, which implies that $b^{\prime}\left(x^{*}(\mathrm{E}(y))\right)-\mathrm{E}(y)=0$. This is equivalent to

$$
\int_{0}^{\infty}\left[b^{\prime}\left(x^{*}(\mathrm{E}(y))-y\right] f(y) d y=0 .\right.
$$

It will now be shown that (4) implies

$$
\int_{0}^{\infty}\left[b^{\prime}\left(x^{*}(\mathrm{E}(y)+p y)-y\right] f(y) d y>0 .\right.
$$

To this end, rewrite (4) as

$$
\int_{0}^{\mathrm{E}(y)}\left[b^{\prime}\left(x^{*}(\mathrm{E}(y))-y\right] f(y) d y+\int_{\mathrm{E}(y)}^{\infty}\left[b^{\prime}\left(x^{*}(\mathrm{E}(y))-y\right] f(y) d y=0 .\right.\right.
$$

The first term in (6) is positive, since the integrand is positive for each $y<\mathrm{E}(y)$. This claim about (6) is readily seen from Figure 1. In particular, in region A, an upward movement in the line $x^{*}(\mathrm{E}(y))$ brings $x$ closer to the optimum $x^{*}(y)$ at each $y$, and given the concavity of welfare $b(x)-x y$ in $x$, this change in $x$ increases welfare. ${ }^{5}$ The second term in (6) is negative, since the integrand is negative for each $y>\mathrm{E}(y)$. The explanation is analagous to what was just stated; in regions $\mathrm{B}$ and $\mathrm{C}$, an upward movement in the line $x^{*}(\mathrm{E}(y))$ makes $x$ more distant from $x^{*}(y)$ and thus lowers welfare at each $y$.

\footnotetext{
${ }^{5}$ That is, $b^{\prime}(x)-y=0$ at $x^{*}(y)$, and thus $b^{\prime}(x)-y>0$ for $x<x^{*}(y)$ since $b^{\prime \prime}(x)<0$. Hence,
} $b^{\prime}\left(x^{*}(\mathrm{E}(y))-y>0\right.$, since, for each $y$ in $\mathrm{A}, x^{*}(\mathrm{E}(y))<x^{*}(y)$. I will omit further explanations like this one that are easy to verify from concavity of $b(x)-x y$ in $x$. 


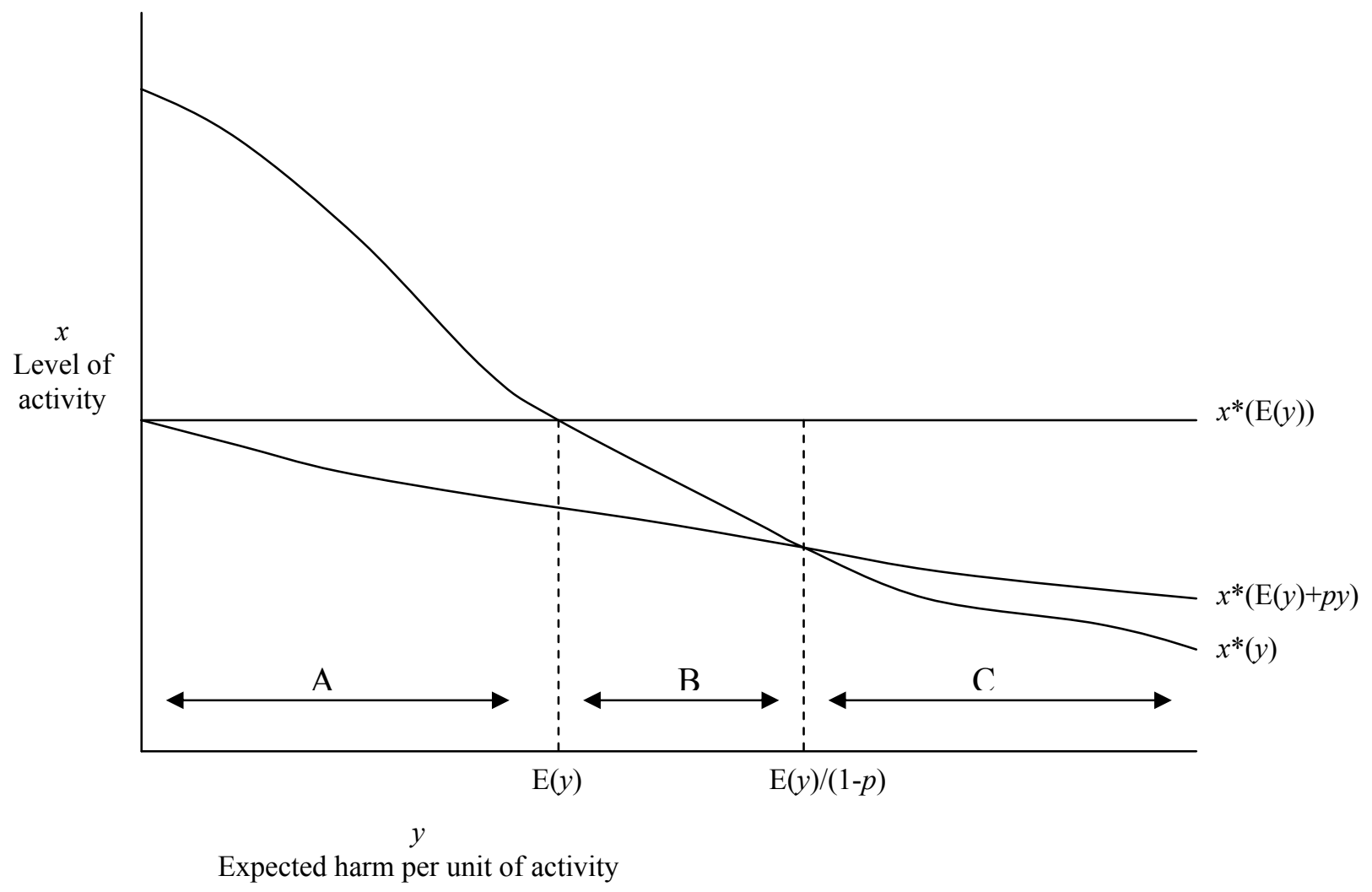

Figure 1 
Next, observe that

$$
\int_{0}^{\mathrm{E}(y)}\left[b^{\prime}\left(x^{*}(\mathrm{E}(y)+p y)-y\right] f(y) d y>\int_{0}^{\mathrm{E}(y)}\left[b^{\prime}\left(x^{*}(\mathrm{E}(y))-y\right] f(y) d y .\right.\right.
$$

This also can be seen from Figure 1. In region $\mathrm{A}$, an increase in $x$ from $x *(\mathrm{E}(y)+p y)$ will increase welfare more than an increase in $x$ from $x^{*}(\mathrm{E}(y))$ since the former is more distant from $x^{*}(y)$ and welfare is concave in $\mathrm{x}$. Similarly, we have that

$$
\int_{\mathrm{E}(\mathrm{y})}^{\infty}\left[b^{\prime}\left(x^{*}(\mathrm{E}(y)+p y)-y\right] f(y) d y>\int_{\mathrm{E}(\mathrm{y})}^{\infty}\left[b^{\prime}\left(x^{*}(\mathrm{E}(y))-y\right] f(y) d y .\right.\right.
$$

To explain, in region $\mathrm{B}$, an increase in $x$ from $x^{*}(\mathrm{E}(y)+p y)$ will raise welfare since $x$ will become closer to $x^{*}(y)$, whereas an increase in $x$ from $x^{*}(\mathrm{E}(y))$ will lower welfare since $x$ will become farther from $x^{*}(y)$. In region $\mathrm{C}$, an increase in $x$ from $x^{*}(\mathrm{E}(y)+p y)$ will reduce welfare by less than an increase in $x$ from $x^{*}(\mathrm{E}(y))$ since the former is closer to $x^{*}(y)$. Hence, over both regions $\mathrm{B}$ and $\mathrm{C}, b^{\prime}\left(x^{*}(\mathrm{E}(y)+p y)-y>b^{\prime}\left(x^{*}(\mathrm{E}(y))-y\right.\right.$, from which (8) follows. Finally, (7) and (8) imply (5).

I now show that (5) implies (3) given the assumption that $b$ displays decreasing absolute risk aversion. Note first that the integrand of (3) equals the integrand of (5) multiplied by $x^{*^{\prime}}(\mathrm{E}(y)+p y)$.

I first claim that $x^{* \prime}(\mathrm{E}(y)+p y)<0$ and that it increases with $y$. To verify this, observe first that $x^{* \prime}(\mathrm{E}(y)+p y)=1 / b^{\prime \prime}\left(x^{*}(\mathrm{E}(y)+p y)\right)<0$, for differentiation of $b^{\prime}(x(t))=$ $t+p y$ with respect to $t$ gives $x^{\prime}(t)=1 / b^{\prime \prime}(x(t))$. Second, note that $x^{* \prime}(\mathrm{E}(y)+p y)$ will increase with $y$ if $b^{\prime \prime \prime}(x)>0$. In particular, differentiation of $x^{\prime}(t)=1 / b^{\prime \prime}(x(t))$ gives $x^{\prime \prime}(t)=$ $-b^{\prime \prime \prime}(x(t)) x^{\prime}(t) /\left[b^{\prime \prime}(x(t))\right]^{2}$, so that the sign of $x^{\prime \prime}(t)$ equals the sign of $b^{\prime \prime \prime}(x(t))$. The assumption of decreasing absolute risk aversion implies that $b^{\prime \prime \prime}(x(t))>0$, for this assumption means that $-b^{\prime \prime}(x) / b^{\prime}(x)$ decreases with $x$.

I now show that (3) holds. Recall that I demonstrated above that $\left[b^{\prime}\left(x^{*}(\mathrm{E}(y)+p y)\right.\right.$ $-y]$ is positive over regions $\mathrm{A}$ and $\mathrm{B}$ and negative over region $\mathrm{C}$, and that $\int_{0}^{\infty}\left[b^{\prime}\left(x^{*}(\mathrm{E}(y)+\right.\right.$ $p y)-y] f(y) d y>0$. It will follow that for any function $w(y)$ such that $w(y)>0$ and $w^{\prime}(y)<$ 0 , we must have

$$
\int_{0}^{\infty} w(y)\left[b^{\prime}\left(x^{*}(\mathrm{E}(y)+p y)-y\right] f(y) d y>0 .\right.
$$

To show (9), let $w^{*}$ equal $w(\mathrm{E}(y) /(1-p))$, namely, the value of $w$ at the point between regions $\mathrm{B}$ and $\mathrm{C}$. Then we have

$$
\int_{0}^{\infty} w(y)\left[b^{\prime}\left(x^{*}(\mathrm{E}(y)+p y)-y\right] f(y) d y>\int_{0}^{\infty} w^{*}\left[b^{\prime}\left(x^{*}(\mathrm{E}(y)+p y)-y\right] f(y) d y,\right.\right.
$$

since $w(y)\left[b^{\prime}\left(x^{*}(\mathrm{E}(y)+p y)-y\right] f(y)>w^{*}\left[b^{\prime}\left(x^{*}(\mathrm{E}(y)+p y)-y\right] f(y)\right.\right.$ for $y<\mathrm{E}(y) /(1-p)$ (because for such $y, w(y)>w^{*}$ and $\left[b^{\prime}\left(x^{*}(\mathrm{E}(y)+p y)-y\right] f(y)>0\right)$ as well as for $y>$ $\mathrm{E}(y) /(1-p)$ (because for such $y, w(y)<w^{*}$ and $\left[b^{\prime}\left(x^{*}(\mathrm{E}(y)+p y)-y\right] f(y)<0\right)$. But

$$
\int_{0}^{\infty} w^{*}\left[b^{\prime}\left(x^{*}(\mathrm{E}(y)+p y)-y\right] f(y) d y=w_{0}^{*} \int_{0}^{\infty}\left[b^{\prime}(x *(\mathrm{E}(y)+p y)-y] f(y) d y>0,\right.\right.
$$

since $\mathrm{w}^{*}>0$ and (5) holds. Hence, (9) is established. Now since $x^{* \prime}(\mathrm{E}(y)+p y)<0$ and increases with $\mathrm{y}$, we know that $-x^{* \prime}(\mathrm{E}(y)+p y)>0$ and decreases with $y$. Thus, $-x^{* \prime}(\mathrm{E}(y)+p y)$ may play the role of $w(y)$, so that (9) implies

$$
-\int_{0}^{\infty} x^{* \prime}(\mathrm{E}(y)+p y)\left[b^{\prime}\left(x^{*}(\mathrm{E}(y)+p y)-y\right] f(y) d y>0,\right.
$$

which is equivalent to (3).

Finally, the argument that has been given would apply essentially unchanged for any $t>\mathrm{E}(y)$ and would show that $W_{T L}(t)<0$. The only difference would be that the 
graph of $x^{*}(t+p y)$ would lie below that of $x^{*}(\mathrm{E}(y)+p y)$ in Figure 1; but this would not affect the logic of any of the steps of the proof. 